NBER WORKING PAPER SERIES

\title{
INFLATIONARY EXPECTATIONS AND PRICE SETTING BEHAVIOR
}

\author{
Ray C. Fair
}

Working Paper No. 3102

\author{
NATIONAL BUREAU OF ECONOMIC RESEARCH \\ 1050 Massachusetts Avenue \\ Cambridge, MA 02138 \\ September 1989
}

This paper is part of NBER's research program in Economic Fluctuations. Any opinions expressed are those of the author not those of the National Bureau of Economic Research. 
NBER Working Paper \#3102

September 1989

\section{INFLATIONARY EXPECTATIONS AND PRICE SETTING BEHAVIOR}

\section{ABSTRACT}

This paper tests for the existence of expectational effects in very disaggregate price equations. Price equations are estimated using monthly data for each of 40 products. The dynamic specification of the equations is also tested, including whether the equations should be specified in level form or in change form. Two expectational hypotheses are used, one in which expectations of the aggregate price level are a function of the past values of the price level and one in which expectations are rational. Under the first hypothesis the lag length is estimated along with the other parameters, and under the second hypothesis the lead length is estimated along with the other parameters.

The results strongly support the hypothesis that aggregate price expectations affect individual pricing decisions. The results do not discriminate very well between the level and change forms of the price equation, although there is a slight edge for the level form. The lag and lead lengths are not estimated precisely, but in most cases the lag length is less than 30 months and the lead length is less than 5 months.

Ray C. Fair Cowles Foundation Box 2125, Yale Station

New Haven, CT 06520 


\section{Introduction}

It is often said that expectations of future prices may affect current prices. If a firm expects that its competitors are going to raise their prices, the firm may raise its own price. In the standard monopolistic competition model, an increase in the prices of a firm's competitors shifts out the demand curve facing the firm, as consumers shift away from the higher price competitors, which increases the firm's profit maximizing price. Therefore, if a firm expects that its competitors are going to raise their prices, this shifts out the expected demand curve that it faces, which leads it to raise its own price. If all firms are behaving in this way, everyone will be raising their prices because they expect that all others are, and in this way expectations can become self fulfilling. Because of this, it is argued, inflation may be difficult to stop quickly. Expectations need to be changed, and this may take a long time.

An important empirical question is whether there is anything to this story? This paper tries to answer this question by estimating expectational effects in very disaggregate price equations. Monthly price data for 40 products have been collected, and price equations are estimated for each of these products. Expectational effects are examined by adding an aggregate price expectations variable to the equations. Various specification tests of the price equations are also performed, including a test of whether the equations should be specified in level form or in change form. The use of 
the highly disaggregate data for these tests may allow more confidence to be placed on them than on similar tests using aggregate data.

Two expectational hypotheses have been used regarding expectations of the aggregate price variable (PA). The first is that the expected future values of PA are a function of its past values. In this case the coefficients are assumed to lie on a linear polynomial with an end point constraint of zero at lag length $q$. q is estimated along with the other parameters, and the standard error of the estimate of $q$ is computed along with the standard errors of the other estimated parameters. The method for estimating $q$ and its standard error is discussed in Andrews and Fair (1989). Estimating the lag length avoids misspecification from picking an incorrect lag length and allows the data to indicate how far back agents look in forming their expectations (under the assumption that the first expectational hypothesis is valid). Estimating the standard errors of the lag-length estimates allows one to see how much confidence to place on the particular estimated lengths.

The second expectational hypothesis is that expectations are rational. In this case the coefficients of the expected future values that enter the equation are assumed to lie on a linear polynomial with a constraint of zero at lead length $r$. $r$ is estimated along with the other parameters, and the standard error of the estimate of $r$ is computed along with the other standard errors. The method for estimating $r$ and its standard error is also discussed in Andrews and Fair (1989). The method is a combination of Hansen's (1982) method of moments, Almon's (1965) polynomial distributed lag (PDL) technique, and the adjustments that are needed to allow $r$ to be estimated. In this case polynomial distributed leads are estimated instead 
of polynomial distributed lags. An estimate of $r$ is an estimate of the length ahead that expectations matter for current decisions.

The tests that were performed are discussed in Section II; the data and variables are explained in Section III; and the results are presented in Section IV.

\section{The Tests}

A standard price equation contains cost variables and demand-pressure variables. In the monopolistically competitive model one can consider the cost variables as representing the marginal cost (MC) curve of the firm. An increase in the price of some input shifts the MC curve up and leads the firm to raise its price. The demand curve facing the firm shifts when general industry demand conditions change and when the prices charged by other firms in the industry change. The demand-pressure variables can be thought of as trying to pick up the effects of general demand conditions on price setting behavior. An increase in industry demand shifts the demand curve facing the firm out and leads the firm to raise its price.

Let $P_{t}$ denote the $\log$ of the price of a firm's good in period $t$, and let $x_{t}$ denote a vector of cost and demand-pressure variables that may affect $P_{t} \cdot 1$ Write the price equation as (1) $P_{t}=x_{t}^{\beta}+u_{t}, t-1, \ldots, T$, where $\beta$ is a vector of parameters to be estimated and $u_{t}$ is an error term.

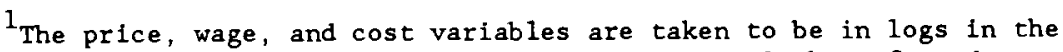
empirical work. For ease of exposition, $P_{t}$ will simple be referred to as the price rather than the log of the price, and similarly for the wage and cost variables. 
The aim of this paper is to try to test for expectational effects in an equation like ( 1 ). Let $\mathrm{PA}_{t+j}^{\mathrm{e}}$ be the firm's expectation of the $\log$ of the aggregate price level in period $t+j(j \geq 0)$, the expectation being made at the beginning of period $t$ (before information for period $t$ is available). Adding $P A_{t}^{e}, P A_{t+1}^{e}$, etc. to equation (1) provides a test of whether expectations matter. If $\mathrm{x}_{t}$ adequately captures all the non expectational variables that affect $P_{t}$ and if expectations don't matter, then $\mathrm{PA}_{t}{ }^{\mathrm{e}}, \mathrm{PA}_{t+1}^{\mathrm{e}}$, etc. do not belong in the equation and should not be statistically significant. If they are significant, this is evidence in favor of the existence of expectational effects.

The danger with this approach is that one may have left out important explanatory variables from $X_{t}$ that are correlated with the $P_{t+j}^{e}$ variables. Too much will then be attributed to the expectations variables. To guard against this, many variables have been included in $x_{t}$. The aim has been to err on the side of too many variables rather than too few. As discussed in the next section, more than one demand-pressure variable has been included in each equation and a number of cost variables have been included. In addition, a linear time trend and seasonal dummy variables have been included. 2 Finally, a fairly rich dynamic specification has been used for some of the equations. Because of the large number of variables included in $X_{t}$, some highly correlated with others, many of the individual parameters are not estimated precisely. This is not, however, of direct concern here. The concern here is simply whether the $\mathrm{PA}_{t+j}^{e}$ variables have independent

2 Even though most of the variables in the estimated equations are seasonally adjusted, the seasonal dummies were included to pick up possible seasonal effects not captured in the data. This procedure is consistent with the theme of erring on the side of too many rather than too few variables in $x_{t}$. 
explanatory power in the equations once all the other variables have been included in $\mathrm{X}_{t}$.

\section{The Expectational Hyootheses and Estimation Techniques}

As noted in the Introduction, two expectational hypotheses have been used in the empirical work regarding the expectations of the aggregate price level. The first is that the expected future values of PA are a function of its past values. The coefficients of the past values of PA are assumed to lie on a linear polynomial that is constrained to be zero at lag length q. The equation that is estimated is

(2) $P_{t}-x_{t} \beta+\int_{0}^{q} \alpha_{[j]} P A_{t-1-[j]} d j+u_{t}, t=1, \ldots, T$

$$
=\mathrm{x}_{t} \beta+\sum_{j=0}^{[\mathrm{q}]-1} \alpha_{j} \mathrm{PA}_{t-1-j}+(\mathrm{q}-[\mathrm{q}]) \alpha_{[\mathrm{q}]} \mathrm{PA}_{t-1-[\mathrm{q}]}+\mathrm{u}_{t}, t-1, \ldots, \mathrm{T},
$$

(3) $a_{j}=\gamma_{0}+\gamma_{1} j, j=0,1, \ldots,[q], q$,

(4) $a_{\mathrm{q}}=0$,

where $q$ is a real number greater than or equal to 1 , and [q] is the integer part of q. Equations (3) and (4) imply that

(5) $\alpha_{j}=-\gamma_{1}(q-j)$.

Given (4) and (5), equation (2) can be written as

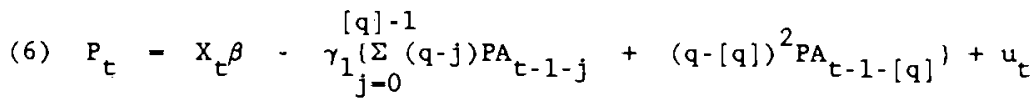

$-x_{t}^{\beta}-\gamma_{1} Q_{t}+u_{t}$. 
This specification extends the traditional PDL setup by allowing $q$ to be real-valued rather than integer-valued. This extension plus the specification in (2) yields a regression function that is differentiable in q. Therefore, the model is simply a nonlinear regression model, and under standard assumptions the least squares estimate of $q$ and various functions of $q$ and the other parameters, such as the sum of the PDL coefficients, are consistent and asymptotically normal. If the errors are iid and normally distributed, the estimates are also asymptotically efficient.

Given $q$, equation (6) is linear in coefficients, and so one way to estimate (6) is to search over $q$ by running least squares regressions to find the value of $q$ that leads to the smallest overall sum of squared residuals. Alternatively, since (6) is differentiable in $q$, a gradient method can be used to compute the estimates. Given the parameter estimates, the covariance matrix of the estimates, including the estimate of $q$, is easy to compute. The formula is given in Andrews and Fair (1989).

In most PDL applications one is interested in the sum $\lambda$ of the lag coefficients. In the present context $\lambda$ is given by (7) $\lambda-\int_{0}^{q} \alpha_{[j]} d j=-\gamma_{1} \int_{0}^{q}(q-[j]) d j-\gamma_{1}\left(\sum_{j=0}^{[q]-1}(q-j)+(q-[q])^{2}\right)$. The formula for the asymptotic variance of the estimate of $\lambda$, $\wedge[\hat{q}]-I_{\hat{q}}$ $-\hat{\gamma}_{1}\left(\underset{j=0}{[q}(\hat{q}-j)+(\hat{q}-[\hat{q}])^{2}\right)$, is given in Andrews and Fair $(1989)$.

The second expectational hypothesis is that expectations are rational. The coefficients of the expected future values of PA are assumed to lie on a linear polynomial that is constrained to be zero at lead length $r$. To see how the equation is estimated, let the expectation error for $\mathrm{PA}_{t+j}^{e}$ be (all 
expectations are assumed to be formed at the beginning of period $t$ )

(8) $\varepsilon_{t+j}=P A_{t+j}-P A_{t+j}^{e}, j=0,1, \ldots,[r]$.

The equation that is estimated is

(9) $P_{t}=x_{t} \beta+\int_{0}^{r} \alpha_{[j]} P A_{t+[j]}^{e} d j+u_{t}, t-1, \ldots, T$,

$$
-\mathrm{x}_{t} \beta+\sum_{j=0}^{[r]-1} \alpha_{j} \mathrm{PA}_{t+j}+(r-[r]) \alpha_{[r]} \mathrm{PA}_{t+[r]}+v_{t}, t=1, \ldots, \mathrm{T},
$$

where

$$
\left.v_{t}=\int_{0}^{r} \alpha_{[j]}^{\epsilon} t+[j]\right]^{d j}+u_{t}
$$

Given (3) and (4) with $r$ replacing $q$, equation (9) becomes

$$
\text { (11) } \begin{aligned}
P_{t} & =x_{t} \beta-\gamma_{1}[\Sigma]-1 \\
j=0 & \left.(r-j) P A_{t+j}+(r-[r])^{2} P A_{t+[r]}\right)+v_{t} \\
& =x_{t}^{\beta}-\gamma_{1} R_{t}+v_{t} .
\end{aligned}
$$

Consider first 2SLS estimation of (11). Let $z_{t}$ be a vector of first stage regressors. A necessary condition for consistency is that $z_{t}$ and $v_{t}$ be uncorrelated. This will be true if both $u_{t}$ and the $\epsilon_{t+j}$ are mean zero and uncorrelated with $z_{t}$. The assumption that $u_{t}$ is mean zero and uncorrelated with $z_{t}$ is the usual 2SLs assumption. The assumption that the $\epsilon_{t+j}$ are mean zero and uncorrelated with $z_{t}$ is the rational expectations assumption. If expectations are formed rationally and if the variables in $z_{t}$ are used (perhaps along with others) in forming the expectations of the $P A_{t+j}$, then $Z_{t}$ and the $\epsilon_{t+j}$ are uncorrelated. Therefore, given this assumption (and the other standard assumptions that are necessary for consistency), the 2SLS estimator of $\beta, \gamma_{1}$, and $r$ is consistent. 
A problem with the 2SLS estimator in this context is that it ignores the m-dependent property of $v_{t}$. Because of the $\varepsilon_{t+j}$, $v_{t}$ will in general be $m-d e p e n d e n t$ with $m-[r]-1$ if $r$ is not an integer and $m-[r]-2$ if $r$ is an integer. The 2SLS estimates are consistent, but the standard formula for their covariance matrix is incorrect and the estimates are not efficient within the class of limited information estimators. Hansen's (1982) method of moments estimator takes account of the m-dependent character of $v_{t}$. It requires that a matrix $M$ be obtained, where $M$ is a consistent estimate of $\lim T^{-1} E\left(z^{\prime} v^{\prime} Z\right)$, where $v^{\prime}-\left(v_{1}, \ldots, v_{T}\right)$ and $z^{\prime}-\left(z_{1}, \ldots, z_{T}\right)$. The exact way in which Hansen's method is applied in this case is discussed in Andrews and Fair (1989), where the formula for the covariance of the parameter estimates, including the estimate of $r$, is also presented.

As mentioned above, the vector $z_{t}$ consists of all or at least a subset of the variables used by agents at the beginning of period $t$ in forming their expectations for periods $t$ and beyond. The expectations must be rational in order for the parameter estimates to be consistent (otherwise $z_{t}$ and the $\varepsilon_{t+j}$ will not necessarily be uncorrelated), but $z_{t}$ need not include all the variables used by agents in forming their expectations. The variables used for $z_{t}$ for the empirical work in this paper are discussed in the next section.

\section{Dynamic Specifications}

It is of interest to see if the disaggregate data used in this study can discriminate among various dynamic specifications of the price equation. A key issue is whether the price equation should be specified in level form or in change form. Theory is not very precise on which specification is 
likely to be better, although in the monopolistic competition model the choice variable is really the price level, not the change in the price. At any rate, it is possible to test empirically which specification is better, which is done here. Assume for now that equation (6) is to be estimated and that in $x_{t}$ there is only one cost (input price) variable, $I_{t-1}$, one demand pressure variable, $D_{t-1}$, and no seasonal dumy variables. ${ }^{3}$ In level form the price equation is taken to be

$$
P_{t}=\beta_{0}+\beta_{1} t+\beta_{2} D_{t-1}+\beta_{3} I_{t-1}+\beta_{4} P_{t-1}-\gamma_{1} Q_{t}+u_{t} .
$$

In change form the equation is taken to be

$$
\begin{aligned}
P_{t}-P_{t-1}= & \eta_{0}+\eta_{1} t+\eta_{2} D_{t-1}+\eta_{3}\left(I_{t-1}-I_{t-2}\right)+\eta_{4}\left(P_{t-1}-P_{t-2}\right) \\
& -\gamma_{1}\left(Q_{t}-Q_{t-1}\right)+u_{t} .
\end{aligned}
$$

Including the time trend $t$ in equation (13) is designed to see if there is a trend in the change in prices not captured by the other explanatory variables; the constant term $\eta_{0}$ picks up the trend in the level of prices not captured by the other variables. Note that $D_{t-1}$, not $D_{t-1}-D_{t-2}$, is in (13). This seems consistent with common practice. For example, in Phillips-curve type equations, the change in prices (or wages) is a function of the level of the unemployment rate, not of the change in the unemployment rate.

It is not possible to nest (12) within (13) or vice versa, but they can each be nested in a more general model. This model is

${ }^{3}$ In the estimation of the equations the cost and demand pressure variables are entered with a lag of one month, and so a lag of one is used for $I$ and $D$ in the following discussion. 
(14) $P_{t}=\delta_{0}+\delta_{1} t+\delta_{2} D_{t}+\delta_{3} I_{t-1}+\delta_{4} I_{t-2}+\delta_{5} P_{t-1}+\delta_{6} P_{t-2}+\delta_{7} Q_{t}$ $+\delta_{8} Q_{t-1}+u_{t}$

The restrictions in (14) implied by the level specification in (12) are $\delta_{4}=$ $\delta_{6}-\delta_{8}-0$. The restrictions in (14) implied by the change specification in (13) are $\delta_{3}=-\delta_{4}, \delta_{5}=-\delta_{6}$, and $\delta_{7}=-\delta_{8}$. These restrictions can be tested. If both sets of restrictions are accepted, 4 then the test has not discriminated between the two specifications. If neither set is accepted, then neither specification is supported by the data. Otherwise, one specification will be selected over the other. In what follows equation (14) will be called the unrestricted form of the price equation.

When the first expectational hypothesis is used, the test of the restrictions is the standard $F$ test. When the second (rational) expectational hypothesis is used, the test is a $x^{2}$ test. The objective function that Hansen's method minimizes is $v^{\prime} \mathrm{ZM}^{-1} \mathrm{Z}^{\prime} \mathrm{v}$, where $v, Z$, and $M$ are defined above. Let $s^{*}$ be the value of the objective function in the unrestricted case, and let $\mathrm{s}^{* *}$ be the value in the restricted case. Then $\left(s^{* *}-s^{*}\right) / T$ is asymptotically distributed as $x^{2}$ with $k$ degrees of freedom, where $k$ is the number of restrictions. A general proof of this is in Andrews and Fair (1987). In performing this test the value of $M$ must be the same for both estimates, and for the results in this paper $M$ was computed using the residuals from the unrestricted equation.

Equations (12) and (13) are also tested against a more general dynamic specification than that in (14). The more general specification is equation (14) with $P_{t-3}, P_{t-4}$, and $P_{t-5}$ added:

${ }^{4}$ By "accepted" is meant that the restrictions are not rejected at whatever confidence level is being used. 


$$
\text { (15) } \begin{aligned}
P_{t}= & \delta_{0}+\delta_{1} t+\delta_{2} D_{t-1}+\delta_{3} I_{t-1}+\delta_{4} I_{t-2}+\delta_{5} P_{t-1}+\delta_{6} P_{t-2}+\delta_{7} Q_{t} \\
& +\delta_{8} Q_{t-1}+\delta_{9} P_{t-3}+\delta_{10} P_{t-4}+\delta_{11} P_{t-5}+u_{t} .
\end{aligned}
$$

The three further restrictions Implied by equations (12) and (13) are then $\delta_{9}-\delta_{10}-\delta_{11}-0$. In other words, testing (12) and (13) against (15) is testing the implicit assumption in (12) and (13) that the further lagged values of the price do not belong in the equation. Equation (15) will be called the general form of the price equation.

The exact equations that were estimated for each product are presented in the next section after the data have been discussed.

\section{The Data}

Monthly price data for 40 products were collected from the data on the producer price indexes compiled by the Bureau of Labor Statistics. The products are listed in Table 1 . They range from chewing gum to rubber hoses. Products were chosen that seemed likely to be fairly homogeneous across time and for which monthly data for a fairly long period of time were available. These data are the date for $P_{t}$. Although ideally one would like price data at the individual firm level, the data collected here are probably as close as one can come to this ideal using government data. In future work it would be interesting to see whether enough data at the individual firm level could be collected to perform the kinds of tests reported in this paper.

The aggregate price variable, $P A_{t}$, was taken to be the producer price index for all commodities. 
TABLE 1

The Forty Products and Their Inputs

1. Chewing gum

1) Raw cane sugar

2) Flavoring syrup (fountain)

3) Cor. shp. cont. for food \& beverages

4) Foil, plain (under .006 inches)

Code

number

02550201

02520101

02640103

09150323

10250111

2. Bottled beer

1) Malt and malt byproducts

2) Cor. shp. cont, for food \& beverages

3) Glass containers

02610101

02640101

09150323

138

3. Cola, bottled, excluding diet cola

02620106

4. Ginger ale

5. Club soda

1) Raw cane sugar

2) Flavoring syrup (fountain)

3) Glass containers

4) Cor. shp. cont. for food \& beverages

5) Kola syrup, for use by bottlers ( 3 only)

02620505

02620507

02520101

02640103

138

09150323

02640105

6. Sole leather

7. Upper leather, including patent

1) Cattle hides

042101

042102

0411

8. Baseball glove

1) Finished cattlehide and kipside leather

15120141

0421

9. Household detergents

1) Fats and oils, inedible

06710402

2) Paperboard

064

091503

10. Shaving soap and cream

11. Cologne and tollet water

06750201

06750305

06750601

067901

1031

2) Metal cans and can components ( 10 only)

4) Fats and o1ls, inedible (12 only)

064

13. Passenger car/motorcycle inner tubes

1) Natural rubber

2) Synthetic rubber

07120221

071101

071102

14. Offset uncoated book paper

15. Unwatermarked bond, no. 4 grade

09130122

16. Cotton fiber writing paper

09130131

17. Newsprint

1) Woodpulp

2) Softwood sulfate, bleached and semibleached 
TABLE 1 (continued)

18. Paperbaord

0914

1) Woodpulp

0911

19. Ice cream carton

09150327

20. Milk carton, $1 / 2$ gallon

09150329

21. Paper cups, hot

09150333

22. File folders

09150645

23. Index cards

09150647

1) Woodpulp

0911

24. Insect wire screening

10880721

10880951

10880213

26. Galvanized nails

1) Plain wire, carbon steel

10170511

27. Wrench, open-end

10420131

28. Wrench, box

29. Adjustable wrench, including pipe

10420132

30. Screwdrivers

31. P1iers

32. Hammers, 1ight forged

1) Bars, c.f., alloy

10420133

10420141

10420151

10420161

0170831

33. Cap screws

10810231

1) Bars, c.f., alloy

0170831

34. Ball and roller bearings

114905

0170831

1) Bars, c.f., alloy

10151351

35. Dry cell size d flashlight batteries

11790211

1) Carbon and graphite products

117903

2) Lead, pig, common

10220127

36. Cutlery, razors and razor blades

1267

10170755

1) Strip, c.v., stainless

13220131

13210101

1) Sand, construction

13210111

38. B1ack lead pencil

15950125

117903

1) Carbon and graphite products

084

2) Other wood products

15970245

39. Toothbrush

40. Rubber hose

071304

071101

1) Natura1 rubber

2) Synthetic rubber

071102 
Table 1 also lists some of the main inputs for each product. Monthly price data on these inputs were also collected. The inputs for each product were chosen through examinations of input-output tables and from talking with various people in the government who are involved in the collection of the data and who are knowledgeable about specific industries. Some of the inputs in Table 1 pertain to more than one product.

The price data in Table 1 are classified by product rather than by industry. The other data that were collected are classified by industry, and Table 2 contains the matching of the industries to the products. The first item under each product is the relevant industry from the industrial production data compiled by the Federal Reserve. Monthly seasonally adjusted data on the production index for each of these industries were collected. Let $\mathrm{Y}_{t}$ denote the production index for a given industry. The data on $Y_{t}$ were used to create a capacity utilization variable, $\mathrm{CU}_{t}$. Peakto-peak interpolations of $\mathrm{Y}_{t}$ were made, and capacity, $C_{t}$, was assumed to lie on the interpolation Iines. Given $C_{t}, \mathrm{CU}_{t}$ is equal to $\mathrm{Y}_{t} / \mathrm{C}_{t}$. If capacity utilization is large (close to one), this may indicate that the demand curve facing the firm has shifted out, which may lead the firm to raise its price. The one-month lagged value of $\mathrm{CU}_{t}, \mathrm{CU}_{t-1}$, was taken to be one of the demandpressure variables to be included in $\mathrm{x}_{t}$.

The second item in Table 2 under each product is the relevant industry from the shipments and inventory data compiled by the Bureau of the Census. Monthly seasonally adjusted data on inventories and shipments were collected for each of these industries. Let $v_{t}$ denote the stock of inventories at the end of month $t$, and let $s_{t}$ denote the level of shipments in month $t$. If the ratio of inventories to shipments, $v_{t} / s_{t}$, is low, this may also indicate 
TABLE 2

The Forty Products and Their Industry Matching

1. Chewing gum
1) none
2) Al1 other foods 64
3) Confectionery products 2065

2. Bottled beer

1) Beer and ale 2082,3

2) Beverages 62

3) Malt beverages 2082

3. Cola, bottled, excluding diet cola

4. Ginger ale

5. Club soda

1) Soft drinks 2086,7

2) Beverages 62

3) Bottled and canned soft drinks 2086

6. Sole leather

7. Upper leather, Including patent

1) Leather and products 31

2) Leather, industrial products, and cut stock 94

3) Leather and leather products 31

8. Baseball glove

1) Personal leather goods $313,5-7,9$

2) Other leather products 95

3) Leather and leather products 31

9. Household detergents

1) Soap and tolletries 284

2) Drugs, soaps, and tolletries 85

3) Soap and other detergents 2841

10. Shaving soap and cream

11. Cologne and toilet water

12. Cleansing creams

1) Soap and tolletries 284

2) Drugs, soaps, and tolletries 85

3) Tollet preparations 2844

13. Passenger car/motorcycle inner tubes

1) Tires 301

2) Tires and tubes 92

3) Tires and inner tubes 301 
TABLE 2 (continued)

14. Offset uncoated book paper

15. Unwatermarked bond, no. 4 grade

16. Cotton fiber writing paper

17. Newsprint

1) Paper 262

2) Pulp and paperboard mills, except biliding paper 74

3) Paper and allied products 26

18. Paperboará

1) Paperboard 263

2) Paperboard containers 76

3) Paperboard mills 263

19.. Ice cream carton

20. Milk carton, $1 / 2$ gallon

21. Paper cups, hot

1) Paperboard containers 265

2) Paperboard containers 76

3) Paperboard containers and boxes 265

22. File folders

23. Index cards

1) Converted paper products 264

2) Paperboard containers 76

3) Paperboard containers and boxes 265

24. Insect wire screening

25. Barbed and twisted steel wire

26. Galvanized nails

1) Fabricated metal products 34

2) Building materials and wire products 18

3) Misc. fabricated wire products 3496

27. Wrench, open-end

28. Wrench, box

29. Adjustable wrench, including pipe

30. Screwdrivers

31. Pliers

32. Hammers, light forged.

1) Hardware, tools, anc cutlery 342

2) Cutlery, hand tools, and hardware 17

3) Hand and edge tools, and handsaws 3423,5

33. Cap screws

1) Fasteners, stampings, etc. 345-7

2) Other fabricated metal products 20

3) Screw machine products 3451

34. Ball and roller bearings

1) Special and general industrial equipment 355

2) Miscellaneous equipment 26

3) Ball and roller bearings 3562 
35. Dry cell size d flashlight batteries

1) Replacement storage batteries 3691

2) Electronic components 38

3) Storage batteries 3691

36. Cutlery, razors and razor blades

1) Hardware, tools, and cutlery 342

2) Cutlery, hand tools, and hardware 17

3) Cutlery, hand tools, and hardwate 342

37. Portland cement

1) Cement 324

2) Other stone, clay, and glass products 09

3) Cement, hydraulic 324

38. Black lead pencil

1) Miscellaneous business supplies 395,9

2) Other durable goods 53

3) Pens, pencils, office and art supplies 395

39. Toothbrush

1) Plastics products, n.e.c. 307

2) Other rubber and plastics products, n.e.c. 93

3) Miscellaneous plastics products 307

40. Rubber hose

1) Rubber products excluding tires $302-4,6$

2) Other rubber and plastics products, n.e.c. 93

3) Reclaimed rubber, hose and belting 303,4

Notes: 1) Industrial production data from the Federal Reserve - data for CU.

2) Shipments and inventories data from the Bureau of the Census -. data for $S$ and $V$.

3) Employment, hours, and earnings data from the Bureau of Labor Statistics - - data for $W, W T, H$, and HO.

The numbers following 1 ) and 3) are SIC industry codes.

The numbers following 2) are product codes used by the Bureau of the Census. 
that the demand curve facing the firm has shifted out, which may lead the firm to raise its price. $v_{t-1} / S_{t-1}$ was also taken to be one of the demandpressure variables to be included in $x_{t}$.

The third item in Table 2 under each product is the relevant industry from the employment, hours, and earnings data compiled by the Bureau of Labor Statistics. Monthly seasonally adjusted data on wage rates, hours, and overtime hours were collected for each of these industries. Let WT denote the average hourly wage, $H_{t}$ the number of hours worked per week, and ${ }^{30}{ }_{t}$ the number of overtime hours worked per week. WT ${ }_{t}$ is not adjusted for overtime hours, and so a new wage variable, $W_{t}$, was constructed, where $W_{t}=$ $\left(W_{t} H_{t}\right) /\left(H_{t}+.5 \mathrm{HO}_{t}\right)$. $W_{t}$ is adjusted for overtime hours under the assumption shat overtime hours are paid time and a half. For some industries not enough data on $\mathrm{H}_{t}$ and $\mathrm{HO}_{t}$ were available to construct $\mathrm{W}_{t}$, and in these cases WT $t$ was used in place of $W_{t}$.

$W_{t-1}$ (or $W T_{t-1}$ ) was included in $x_{t}$ as one of the cost variables. In addition, the one-month lagged ratio of overtime hours to total hours, ${ }^{H O} \mathrm{t}_{\mathrm{t}-1} / \mathrm{H}_{\mathrm{t}-1}$, was included in $\mathrm{x}_{t}$ (data permitting) as another demand-pressure variable. If overtime hours are high, this may indicate that the demand curve facing the firm has shifted out, which may lead the firm to raise its price.

Table 3 presents the equations that were estimated for each product and the sample periods that were used. The table is self explanatory, and it will only be briefly discussed here. The change form is equation (12); the level form is equation (13); the unrestricted form is equation (14); and the general form is equation (15). All the sample periods cover the turbulent period of the 1970's. Some are shorter than others because of data 
TABLE 3

The Equations and Sample Periods

Each equation contains a constant term, a linear time trend, and 11 seasonal dummy variables. Let $A_{t}$ denote the vector of these variables for month $t$. Let $P_{\text {it }}$ denote the price of input $i$ for a given product, where the inputs are listed in Table 2. I runs from 1 up to a maximum of 5 . Let $B_{t}$ denote the vector $\left(P_{1 t}, \ldots, P P_{n}\right)$, where $n$ is the number of inputs for the given product ( $n$ may be 1 ). ${ }^{1}$ Let $D B_{t}^{t}$ denote the vector $\left(P_{1 t}-P_{1 t-1}, \ldots, P_{n t}-P_{n t-1}\right)$. The specifications are:

Change Form:

LHS variable: $\quad P_{t}$

RHS variables: $A_{t}, B_{t-1}, W_{t-1}$ or $W T_{t-1}, C U_{t-1}, V_{t-1} / S_{t-1}, H_{t-1} / H_{t-1}, P_{t-1}$ : and $Q_{t}$ or $R_{t}$.

\section{Level Form:}

LHS variable: $P_{t} \cdot P_{t-1}$

RHS variables: $A_{t}, D B_{t-1}, W_{t-1}-W_{t-2}$ or $W T_{t-1}-W T_{t-2}, C U_{t-1}, V_{t-1} / S_{t-1}$, ${ }^{H O}{ }_{t-1} / H_{t-1}, P_{t-1}-P_{t-2}$, and $Q_{t}-Q_{t-1}$ or $R_{t}-R_{t-1}$.

Unrestricted Form:

LHS variable: $P_{t}$

RHS variables: $A_{t}, B_{t-1}, B_{t-2}, W_{t-1}$ or $W T_{t-1}, W_{t-2}$ or $W T T_{t-2}, C U_{t-1}$,

$v_{t-1} / S_{t-1}, H_{t-1} / H_{t-1}, P_{t-1}, P_{t-2}, Q_{t}$ or $R_{t}$, and $Q_{t-1}$

or $R_{t-1}$.

General Form:

LHS variable: $P_{t}$

RHS variables: $A_{t}, B_{t-1}, B_{t-2}, W_{t-1}$ or $W_{t-1}, W_{t-2}$ or $W T_{t-2}, C U_{t-1}$,

$v_{t-1} / S_{t-1}, H_{t-1} / H_{t-1}, P_{t-1}, P_{t-2}, Q_{t}$ or $R_{t}$,

$Q_{t-1}$ or $R_{t-1}, P_{t-3}, P_{t-4}$, and $P_{t-5}$.

Special Features:

Neither $W$ nor WT appear in 24-31 and 35. W appears in 6-8, 13-23, 34, and 36-40. WT appears in $1-5,9-12$, and 32 . HO/H appears only in $6-8,13-$ 23, 34, and 35-40. CU does not appear in 1 . 
TABLE 3 (continued)

$\begin{array}{lllll}\begin{array}{c}\text { Prod- } \\ \text { uct } \\ \text { Period }\end{array} & \mathbf{T} & \mathbf{k}_{1} & \mathbf{k}_{2} \\ 1 & 1961.07-1985.12 & 294 & 21 & 28 \\ 2 & 1967.07-1987.12 & 246 & 21 & 27 \\ 3 & 1969.07-1985.12 & 198 & 23 & 31 \\ 4 & 1961.07-1985.07 & 289 & 22 & 29 \\ 5 & 1961.07-1985.12 & 294 & 22 & 29 \\ 5 & 1958.07-1983.08 & 302 & 20 & 24 \\ 7 & 1958.07-1988.05 & 359 & 20 & 24 \\ 8 & 1958.07-1985.02 & 320 & 20 & 24 \\ 9 & 1958.07-1988.05 & 359 & 20 & 25 \\ 10 & 1958.07-1986.12 & 342 & 20 & 25 \\ 11 & 1958.07-1988.05 & 359 & 20 & 25 \\ 12 & 1958.07-1988.05 & 359 & 20 & 25 \\ 13 & 1958.07-1985.12 & 330 & 21 & 26 \\ 14 & 1958.07-1988.05 & 359 & 21 & 25 \\ 15 & 1958.07-1988.05 & 359 & 21 & 26 \\ 16 & 1958.07-1987.12 & 354 & 21 & 26 \\ 17 & 1958.07-1988.05 & 359 & 21 & 26 \\ 19 & 1958.07-1988.05 & 359 & 20 & 24 \\ 19 & 1964.06-1985.06 & 253 & 20 & 24 \\ 20 & 1964.06-1985.06 & 253 & 20 & 24\end{array}$

$\begin{array}{ccccc}\begin{array}{c}\text { Prod- } \\ \text { uct }\end{array} & \begin{array}{l}\text { Sample } \\ \text { Period }\end{array} & \mathrm{T} & \mathrm{k}_{1} & \mathbf{k}_{2} \\ 21 & 1967.07-1985.06 & 216 & 20 & 24 \\ 22 & 1958.07-1988.05 & 359 & 20 & 24 \\ 23 & 1958.07-1980.07 & 265 & 20 & 24 \\ 24 & 1958.07-1988.05 & 359 & 18 & 21 \\ 25 & 1958.07-1988.05 & 359 & 18 & 21 \\ 26 & 1958.07-1984.07 & 313 & 18 & 21 \\ 27 & 1958.07-1985.10 & 328 & 18 & 21 \\ 28 & 1958.07-1988.05 & 359 & 18 & 21 \\ 29 & 1958.07-1988.05 & 359 & 18 & 21 \\ 30 & 1958.07-1988.05 & 359 & 18 & 21 \\ 31 & 1958.07-1988.05 & 359 & 18 & 21 \\ 32 & 1967.07-1988.05 & 251 & 19 & 23 \\ 33 & 1964.07-1988.05 & 287 & 18 & 21 \\ 34 & 1961.07-1988.05 & 323 & 21 & 26 \\ 35 & 1961.07-1988.05 & 323 & 19 & 23 \\ 36 & 1958.07-1988.05 & 359 & 20 & 24 \\ 37 & 1958.07-1988.05 & 359 & 21 & 25 \\ 38 & 1967.07-1985.12 & 222 & 21 & 26 \\ 39 & 1958.07-1981.12 & 282 & 20 & 24 \\ 40 & 1972.07-1985.12 & 162 & 21 & 26\end{array}$

Notes:

$T$ is the total number of observations. $k_{1}$ is the number of explanatory variables in the change form and
in the level form.

$k_{2}$ is the number of explanatory variables in the unrestricted form.

The number of explanatory variables in the general form is $k_{2}+3$.

Notation:

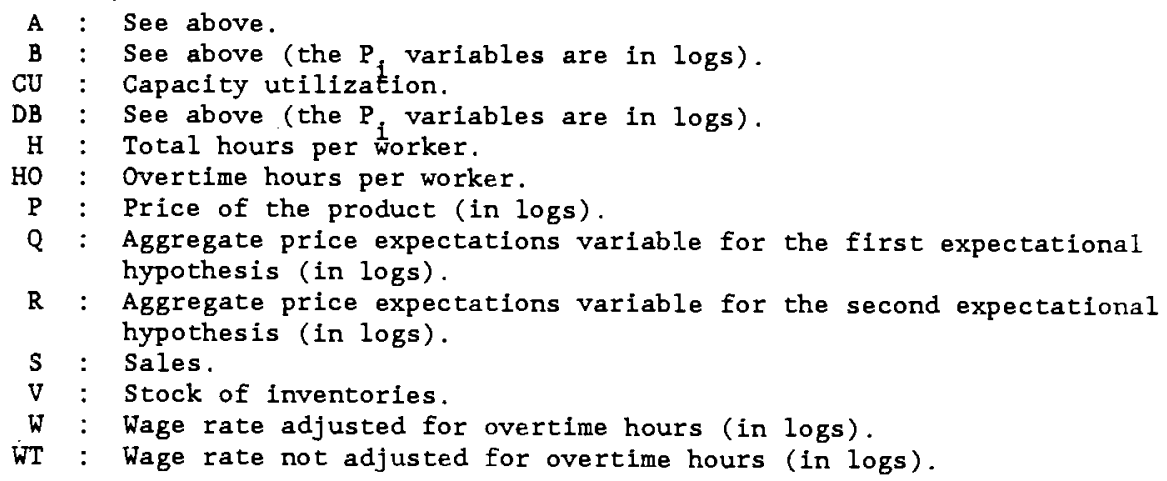


limitations. The number of observations ranges from 162 to 359 . More than half of the sample periods have over 300 observations. The number of explanatory variables in the level and change forms varies from 18 to 23, counting the aggregate price expectations variable as one. 5 The number of explanatory variables in the unrestricted form varies from 21 to 31 . The general form includes three more variables, namely the three lagged values of the price.

When the unrestricted and general forms were estimated, the same value of $q$ was assumed for both $Q_{t}$ and $Q_{t-1}$ and the same value of $r$ was assumed for both $R_{t}$ and $R_{t-I}$. This treatment is consistent with the view that $Q_{t-1}$ is simply $Q_{t}$ lagged one month and that $R_{t-1}$ is simply $R_{t}$ lagged one month.

The variables used for $z_{t}$ under the second (rational) expectations hypothesis are the following. First, all the explanatory variables in the general form of the equation for the given product were used except for $R_{t}$ and $R_{t-1}$ (for all the forms estimated). Second, $P A_{t-1}, P A_{t-2}, P A_{t-3}$, $\mathrm{PA}_{t-4}$, and $\mathrm{PA}_{t-5}$ were used. Finally, the one-month and two-month lagged values of the unemployment rate, the overall industrial production index, the three-month Treasury bill rate, and the 10 -year government bond rate were used. These are the variables that agents are assumed to use (perhaps along with others) in forming their expectations.

It should be noted that $q$ and $r$ cannot be less than one. In a number of cases the optimum occurred at a value of $q$ or $r$ of one, and these are the estimates reported below. Also, a maximum of $q$ of 132 ( 11 years) was set, and in a few cases the optimum occurred at a value of $q$ of 132 . Similarly,

${ }^{5}$ The number of parameters estimated is one greater than the number of explanatory variables listed because the lag length $q$ or the lead length $r$ is estimated along with the other parameters. 
a maximum of $r$ was set at 12 , and in a few cases the optimum occurred at this value.

\section{The Results}

Tables 4 and 5 present a summary of the all the results, and this section is a discussion of these two tables. Table 4 sumarizes the results for the first expectational hypothesis, and Table 5 summarizes the results for the second. A fairly systematic procedure was followed in the estimation work. Consider first the results in Table 4. Four equations were estimated per product ${ }^{6}$ - - the level, change, unrestricted, and general forms - - and from these estimates four $F$ values were computed. The first $F$ value tests the restrictions in the level form relative to the restricted form; the second tests the restrictions in the level form relative to the general form; the third tests the restrictions in change form relative to the unrestricted form; and the fourth tests the restrictions in the change form relative to the general form. 7

If the restrictions implied by the level form are rejected at the 1 percent level in both cases, i.e., compared to both the unrestricted and general forms, the estimates of $\lambda$, the sum of the PDL coefficients, and $q$ are not recorded in Table 4. When these two rejections take place, it is a clear rejection of the level form of the price equation, and so further examination of the equation is not of interest. Similarly, if the

${ }^{6}$ The estimates were obtained by searching over values of $q$. The final grid search was .01. The estimates in Table 5 were obtained by searching over values of $r$. The final grid search in this case was . 1 .

7 The degrees of freedom for the $F$ test (and for the $\chi^{2}$ test in Table 5) can be calculated from the numbers presented in the last half of Table 3 . 
TABLE 4 (continued)

Notes:

significant at the 5 percent level.

** significant at the 1 percent level.

$F_{1}$ F-statistic for the hypothesis that the restrictions in the level form relative to the unrestricted form are valid.

$F_{2}$ F-statistic for the hypothesis that the restrictions in the level form relative to the general form are valid.

$\mathrm{F}_{3} \mathrm{~F}$-statistic for the hypothesis that the restrictions in the change form relative to the unrestricted form are valid.

$\mathrm{F}_{4}$ F-statistic for the hypothesis that the restrictions in the change form relative to the general form are valid.

$F_{5}$ F-statistic for the hypothesis that the coefficients of the price expectations variables $\left(Q_{t}\right.$ and $\left.Q_{t-1}\right)$ in the general form are zero.

$\lambda$ Estimate of $\lambda$, the sum of the PDL coefficients.

$t_{\lambda}$ t-statistic for $\hat{\lambda}$.

$\hat{q}$ Estimate of $q$.

$S E_{q}$ Estimated standard error for $\hat{q}$. 
TABLE 5

Results Using the Second Expectations Hypothes is

Level Form

Change Form

Ceneral Form

Prod-

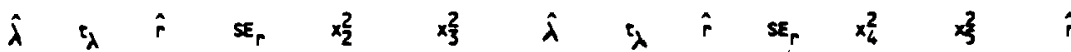

$151.92^{\text {t1 }}$

$2 \quad 4.50$

$321.56^{* *}$

$4 \quad 10.34 \quad .019 \quad 0.60$

$5 \quad 21.51^{* *} .049 \quad 0.89$

$620.38^{* *}$

$761.27^{* *}$

$89.80^{\circ}$

$9 \quad 5.24$

$10 \quad 9.69$

$1150.57^{* \omega}$

$12 \quad 10.78$

139.2

$1411.56^{\circ}$

$1515.57^{\text {th }}$

$1640.17^{\text {t* }}$

$1717.91^{\text {t* }}$

$1839.26^{\circ}$

$19 \quad 2.60$

$20 \mathrm{23.06}^{\mathrm{tt}}$

$21 \quad 1.28$

$2237.39^{\text {t* }}$

$2333.89^{\text {t* }}$

$2418.87^{\circ *}$

$2532.24^{*}$

$26 \quad 4.44$

6.20

3.07

1.75

6.78

.0480 .89

$\begin{array}{lll}.051 & 1.83 \quad 1 .\end{array}$

$\begin{array}{lll}.064 & 3.40 \quad 8.3\end{array}$

$\begin{array}{lll}.099 & 1.97 \quad 1.9\end{array}$

$.075 \quad 2.94 \quad 5.9$

$\begin{array}{lll}.075 & 2.94 & 5.8 \\ .071 & 1.80 & 12.0\end{array}$

$.127 \quad 3.55 \quad 5$.

$.075 \quad 3.05$

$\begin{array}{lll}.050 & 2.87 & 7.9\end{array}$

$\begin{array}{lll}.043 & 2.51 \quad 12.0\end{array}$

$.1153 .64 \quad 1.7$

$59.11^{\mathrm{tt}}$

$42.95 \quad 7.67$

23.89

$18.00^{\circ}$

13.41

$39.74^{\circ}$

$14.31^{\circ}$

$11.5315 .15^{\circ+}$

14.9125 .04

$7.62 \quad 21.32^{* t+}$

$33.68^{m}$

$17.18 \quad 31.27$

$51.3115 .47^{* 4}$

10.84 12.20"

9.7013 .03

$10.9014 .87^{\circ}$

$36.60^{* t *}$

$31.68 \quad 5.09$

15.28

$\begin{array}{lllll}.104 & 2.02 & 7.9 & 10.35 & 6.88\end{array}$

$15.19^{=0}$

$\begin{array}{llllll}.096 & 4.23 & 12.0 & 9.69 & 10.87^{*}\end{array}$

$\begin{array}{llllll}.039 & 1.53 & 12.0 & 34.21 & 8.16^{*}\end{array}$

$\begin{array}{llllll}.086 & 4.28 & 1.9 & 3.15 & 32.13^{\circ *}\end{array}$

$\begin{array}{llllll}.073 & 3.48 \quad 1.9 & 4.63 \quad 34.26 \%\end{array}$

$\begin{array}{llllll}.073 & 3.58 & 9.0 & 21.82 & 14.52\end{array}$

$\begin{array}{lllll}.062 & 4.76 & 12.0 & 16.70 & 13.71^{* t}\end{array}$

\begin{tabular}{rrrrrr}
6.78 & .059 & 2.84 & 1.9 & 5.62 & $26.86^{*}$ \\
\hline 6.14 & 062 & 3.39 & 12.0 & 16.02 & 20.20
\end{tabular}

$\begin{array}{lllllll}18.41^{\circ} & .569 & 1.48 & 2.9 & 2.09 & 12.90^{\circ *} & 3.02\end{array}$

$\begin{array}{llllllll}13.84 & 391 & 2.19 & 8.9 & 8.01 & 20.16^{*} & 1.00\end{array}$

$34.11^{\text {tक }}$

$\begin{array}{llll}16.74 & .564 & 3.09 & 1.0\end{array}$

$38.26 " 1.82$

$22.36 * 1.37$

$29.57^{\circ} \quad .950 \quad 2.88 \quad 1.0 \quad-20.44^{\circ} 4.48$

$\begin{array}{lll}26.01^{* *} & 44.21^{* *} & 9.58{ }^{*} \\ 67.62^{* *} & 20.04^{* *} & 0.92\end{array}$

4.9

$20.66^{\circ}$

8.02

$53.52^{* *}$

$.530 \quad 4.59 \quad 8$.

$6.46 \quad 28.84^{* *}$

$121.45^{\circ}$

$20.08 "$

9.29

$41.24^{\text {t* }}$

$22.45^{\circ}$

56.29

$25.91^{\circ}$

$37.00^{\circ / *}$

10.90

$3.7^{* t+}$

10.07

41.62

$38.89^{\circ}$

$21.07^{*}$

$66.57^{* t}$

$.948 \quad 3.88 \quad 3$.

6.30

$70.28 * 11.16^{*} \quad 3.0$

$78.85^{* *} 12.71^{*} \quad 1.8$

$25.47^{*+}$

3357.92

$3419.56^{* t}$

$3540.89^{* *}$

$37 \quad 5.10$

.03

$\begin{array}{lllll} & & & & 17.73^{\circ} \\ .085 & 3.44 & 12.0 & 12.28 \quad 8.73^{*}\end{array}$

9.22

$.910 \quad 3.20 \quad 4.9$

$6.6935 .88^{* t+}$

$1.700 \quad 4.16 \quad 1.6$

0.5215 .23

$42.86^{\circ}$

$.236 \quad 1.40 \quad 5.9$

9.76

$18.80^{*}$

$28.16^{\text {t"t }}$

$67.57^{* t+}$

$\begin{array}{lllll}.952 & 4.97 & 2.2 & 1.56 & 10.71\end{array}$

$\begin{array}{lll}.668 & 4.39 & 2.9\end{array}$

0.70

$28.91^{\circ}$

$.824 \quad 3.66 \quad 6.8$

$26.00^{\circ}$

$5.78 \quad 13.70$

$18.83^{\text {t* }}$

$19.97^{\text {tht }}$

9.62

$\begin{array}{lll}.935 & 3.81 & 5.9\end{array}$

1.8

$12.94^{\circ}$

$35.62^{* *}$

5.65

$\begin{array}{llll}.967 & 3.81 & 5.9\end{array}$

$3.7744 .70^{\circ}$

$3.8033 .93^{\text {*t }}$

$4.9318 .01^{\mathrm{m}}$

$\begin{array}{llll}15.22 & .870 & 5.27 & 6.9\end{array}$

$4.28 \quad 23.92 *$

$12.69^{\circ}$

$\begin{array}{lll}.780 & 5.27 & 6.9 \\ .697 & 3.58 & 1.4\end{array}$

$0.8233 .48^{\text {"1" }}$

$3.3124 .38^{\circ 1}$

$14.66^{\circ} \quad 1.0$

$26.63^{\circ}$

$.863 \quad 3.75 \quad 4.9$

18.96

$37.62^{* *}$

$29.86^{\star *}$

17.17

3.8

$29.80^{\text {t* }}$

$23.30^{\circ / 4}$

14.58

$42.49^{* *}-.298-1.37$

$17.28^{\circ}$

$\begin{array}{llll}6.73 & .507 & 3.03 & 1.0\end{array}$

$17.54^{\circ \circ}$

$19.53^{* *} \quad 4.8$

$38 \quad 10.55$

.074

$2.12 \quad 4.9$

$13.8613 .89^{\circ}$

6.73

.89

$\begin{array}{lll}.090 & 2.98 & 5.9\end{array}$

$5.1233 .95^{* *}$

14.18

.333

$\begin{array}{ll}4.03 \quad 2.2 \\ 1.64 & 6.8\end{array}$

$2.2239 .51^{\circ *}$

3.19

$\begin{array}{llll}39 & 7.48 & .007 & 0.37\end{array}$

$40 \quad 9.20$

$.055 \quad 1.09$

$19.34^{\circ}$

$\begin{array}{llll}13.01 & .200 \quad 1.10 & 3.6\end{array}$

$9.5827 .68^{* *}$

$8.7^{*} \quad 4.9$

$9.0 \quad 22.22 \quad 34.84=$

$16.85^{\circ}$

$\begin{array}{lll}.609 & 3.52 & 1.7\end{array}$

8.2224 .96 "

$27.34=1.6$

2.4

2.9

3.1

1.9

3.0

7.1

3.9

4.9
1.6
4.9 
TABLE 5 (continued)

Notes:

significant at the 5 percent level.

** significant at the 1 percent level.

$x_{1}^{2} x^{2}$-statistic for the hypothesis that the restrictions in the level form relative to the unrestricted form are valid.

$x_{2}^{2} x^{2}$-statistic for the hypothesis that the restrictions in the level form relative to the general form are valid.

$x_{3}^{2} x^{2}$-statistic for the hypothesis that the restrictions in the change form relative to the unrestricted form are valid.

$x_{4}^{2} x^{2}$-statistic for the hypothesis that the restrictions in the change form relative to the general form are valid.

$x_{5}^{2} x^{2}$-statistic for the hypothesis that the coefficients of the price expectations variables $\left(Q_{t}\right.$ and $\left.Q_{t-1}\right)$ in the general form are zero.

$\lambda$ Estimate of $\lambda$, the sum of the PDL coefficients.

$t_{\lambda} t$-statistic for $\hat{\lambda}$.

$\hat{r}$ Estimate of $r$.

$\mathrm{SE}_{r}$ Estimated standard error for $\hat{r}$. 
restrictions implied by the change form are rejected at the 1 -percent level in both cases, the estimates of $\lambda$ and $q$ are not recorded. Note that this procedure gives the benefit of the doubt to the level and change forms regarding what is recorded in the tables. The estimates are not presented only if the restrictions are rejected at the 1 percent level for both tests. For purposes of reporting the results it seemed better to err on the side of presenting too many estimates than too few.

When the estimates are recorded for a given product, the estimate of $\lambda$ and its t-statistic are presented. The t-statistic tests whether the sum of the coefficients of the past values of the aggregate price variable is significantly different from zero. If the t-statistic is quite low, which is taken here to be less than one, then the aggregate price variable is clearly not significant. In this case it is of no interest to exarnine the estimate of $q$, and so when a t-statistic is less than one in Table 4, the estimate of $q$ is not presented. Similarly, if the estimate of $\lambda$ is negative, which is not sensible, the estimate of $q$ is not presented. When the estimate of $q$ is presented in the table, its estimated standard error is also presented unless the estimate of $q$ is one, which is a corner solution.

A fifth F-statistic is also presented in Table 4. This statistic tests whether $Q_{t}$ and $Q_{t-1}$ are jointly significant in the general form of the equation. Computing this statistic requires that a fifth regression be run for each product, namely the general form without $Q_{t}$ and $Q_{t-1}$ ineluded. This $F$ test is particularly useful when both the level and change forms have been rejected. It tests for the significance of the aggregate price expectations variable in an equation that is less likely to be dynamically misspecified. This test has three degrees of freedom in the numerator, one 
each for $Q_{t}$ and $Q_{t-1}$ and one for $q$. When $Q_{t}$ and $Q_{t-1}$ are jointly significant at the 5 percent level, the estimate of $q$ is also presented in Table 4. This is the estimate of $q$ under the most general dynamic specification.

It will be useful to discuss the results in Table 4 before considering Table 5. Consider the level versus change forms first. Both the level and change forms are rejected in 19 of the 40 cases. For 6 products both forms are rejected, and for 8 products both are accepted. It thus seems at first glance that both forms do about the same. However, for all 8 of the products for which both are accepted, the level form has a better fit (and thus a lower F-statistic) than does the change form. If one counts these cases as a rejection for the change form, the change form is then rejected in 27 of the 40 cases compared to only 19 for the level form. There is thus at least a slight edge in favor of the level form, although only slight.

The estimate of $\lambda$ is significant ${ }^{8}$ in 14 of the 21 cases in which the level form is accepted, and it is significant in 15 of the 21 cases in which the change form is accepted. For the general form the aggregate price expectations variable is significant at the 5 percent level or greater in 23 of the 40 cases. This is thus fairly strong evidence in favor of the hypothesis that aggregate price expectations matter. In over half the cases the price expectations variable is significant.

The estimates of $q$ vary considerably across the products, and in general they have large standard errors. The data clearly seem better at tacking down the sum of the PDL coefficients $(\lambda)$ than they do at choosing

${ }^{8}$ The estimate of $\lambda$ will be said to be significant if its t-statistic is greater than two in Table 4. 
the lag length. It can be seen in the last column in Table 4, however, that the estimates of $q$ in the most general specification are not too variable. Omitting the three largest values $(132.00,132.00$, and 90.10$)$, the range is 4.25 to 30.55 . Agents are thus estimated to look back between about 4 months and 31 months in forming their expectations of the future.

The results for Table 5 were obtained in a similar manner as they were for Table 4, where $\chi^{2}$ tests are used in place of $F$ tests. The only difference is that six equations had to be estimated rather than four. For example, the level form had to be estimated twice, once using the estimate of $M$ computed from the residuals from the unrestricted form and once using the estimate of $M$ from the residuals from the general form. Likewise, the change form had to be estimated twice. Also, for the fifth $\chi^{2}$ test the general form of the equation without $R_{t}$ and $R_{t-1}$ included had to be estimated by Hansen's method using the same $M$ matrix that was used to estimate the general form with the two varlables included.

The results in Table 5 are qualitatively similar to those in Table 4. The level form is rejected in 12 of the 40 cases, and the change form is rejected in 16 of the 40 cases. These compare to 19 each in Table 4 . For 10 products both forms are rejected, compared to 6 in Table 4 , and for 22 products both are accepted, compared to only 8 in Table 4 . There is thus less discrimination between the two forms in Table 5 than in Table 4 , although the level form still has a slight edge.

The estimate of $\lambda$ is signiflcant in 19 of the 28 cases in which the level form is accepted, and it is significant in 19 of the 24 cases in which the change form is accepted. For the general form the aggregate price expectations variable is significant at the 5 percent level or greater in 23 
of the 40 cases. Again, as in Table 4, this is fairly strong evidence in favor of the hypothesis that aggregate price expectations matter.

The estimates of $r$ in Table 5 range from 1.0 to 12.0 , the minimum and maximum allowed. Of the 71 estimates of $r$ presented, counting the estimates for the general form, four are 1.0 and nine are 12.0. If for the general foril the two largest estimates of $r$ are excluded $(12.0$ and 7.1$)$, the estimates range from 1.0 to 4.9 . In most cases the horizon thus seems to be less than six months regarding the effect of future expectations on current decisions.

\section{v. Conclusion}

The results in Tables 4 and 5 strongly support the hypothesis that aggregate price expectations affect individual pricing decisions. Even under the most general dynamic specification, the expectations variables are significant in over half of the cases. The results do not discriminate very well between the level and change forms of the price equation. There is a slight edge for the level form, but only slight. The lag length for the first expectational hypothesis is not estimated precisely, although in most cases it is less than 30 months. The lead length for the second (rational) expectational hypothesis is less than 5 months in most cases, although it too is not estimated precisely.

As noted in Section III, it would be interesting in future work to see if tests similar to those performed in this paper could be performed using individual firm data. The better the data, the less likely is it that the price equation has omitted variables that are correlated with the aggregate price expectations variable, thus biasing the results in favor of the 
expectations hypothesis.

In future work with individual firm data it might also be of interest to test the first (naive) expectational hypothesis against the second (rational) one. No attempt was made to test the two hypotheses in this paper. Collinearity problems are likely to be severe in carrying out this test, and the main conclusions of this paper are not sensitive to the particular hypothesis used. 9

${ }^{9}$ The rational expectations hypothesis is tested in Fair (1989) using aggregate data, and the results provide only mild support for it. 


\section{REFERENCES}

Almon, Shirley, "The Distributed Lag Between Capital Appropriations and Expenditures," Econometrica, 33 (January 1965), 178-196.

Andrews, Donald W.K., and Ray C. Falr, "Estimation of Polynomlal Distributed Lags and Leads with End Point Constraints," mimeo, August 1989.

"Inference in Econometric Models with Structural Change," Review of Economic Studies, (October 1988), 615-640.

Fair, Ray C., "Testing the Rational Expectations Hypothesis in Macroeconometric Mode1s," mimeo, May 1989.

Hansen, Lars, "Large Sample Properties of Generalized Method of Moments Estimators," Econometrica, 50 (July 1982), 1029-1054. 